\title{
Diagnosis and Treatment in Vestibular Migraine
} Vestibüler Migrende Tanı ve Tedavi

\author{
(1) Pınar Yalınay Dikmen \\ Acibadem Mehmet Ali Aydinlar University School of Medicine, Department of Neurology, Istanbul, Turkey
}

\begin{abstract}
Vestibular migraine (VM) is the most common cause of recurrent spontaneous vertigo. Inclusion of the diagnostic criteria for VM in the last edition of the International Classification of Headache Disorders published in 2013 promoted the establishment of unity in terminology as well as increasing awareness about VM. The diagnosis of VM is based on clinical history. In studies related to VM, it has been shown that headache and vertigo may not always occur simultaneously, and vertigo may present in different patterns in individual attacks of patients. This variation creates difficulty in the diagnosis of VM. Therefore, the presence of headache should always be questioned in young and middle-aged patients who present with vertigo. Headache that was present previously may have disappeared years ago, hence a detailed patient history is the most essential tool in the diagnosis of VM. There may be some findings showing central and peripheral vestibular involvement in the neurotologic examination during ictal and interictal periods. However, there is no pathognomonic laboratory test; the diagnosis is made clinically. In the differential diagnosis of VM, peripheral vestibular diseases should be excluded, especially Meniérè's disease. For treatment, it is important to determine and control the triggers of headache and vertigo, and regulate the patient's lifestyle and nutrition preferences accordingly. Acute and prophylactic medications for migraine might be used, but prospective and randomized controlled studies are necessary in this regard. Vestibular rehabilitation might be especially effective in suppressing symptoms in patients who are highly dependent on environmental and visual stimuli with impaired physiologic adaptation.
\end{abstract}

Keywords: Vertigo, migraine, vestibular, dizziness, headache

\section{Öz}

Vestibüler migren (VM) tekrar eden spontan vertigonun en sık nedenidir. Tanı kriterlerinin 2013 yılındaki son Baş Ağrısı Hastalıkları Sınıflaması'nda yer alması hem terminoloji birliği oluşmasında, hem de VM ile ilişkili farkındalı̆̆ın artması konusunda yardımcı olmuştur. VM tanısı klinik bir tanıdır. VM ile ilgili çalışmalarda hastaların baş ağrısı ve baş dönmesinin eş zamanlı olmayabileceği, hastaların baş dönmesinin ataklar arasında farklı özellikler göstererek ortaya çıkabileceği gösterilmiştir. Bu tanıda zorluk yaratır. Bu nedenle vertigo şikayeti ile başvuran genç, orta yaşlı hastalarda mutlaka baş ağrısının sorgulanması gerekir. Baş ağrısı yıllar önce olup kaybolmuş olabilir, öykü VM tanısındaki en önemli araçtır. İktal ve interiktal dönemde nörotolojik muayenede santral ve periferik vestibüler tutulumu gösteren bulgular olabilir, ancak patognomik bir laboratuvar incelemesi yoktur, tanı klinik olarak konulur. VM'nin ayırıcı tanısında periferik vestibüler hastalıkların, özellikle Meniérè hastalığının dışlanması gerekir. Tedavide baş ağrısı ve vertigoyu tetikleyen sebeplerin saptanarak kontrol altına alınması, hastanın yaşam tarzı ve beslenme alışkınlıklarının düzenlenmesi önemlidir. Medikal tedavide migren tedavisinde kullanılan akut ve profilaktik ilaçlar denenebilir, ancak bu konuda prospektif, randomize kontrollü çalışmalara ihtiyaç vardır. Vestibüler rehabilitasyon özellikle çevresel ve görsel uyaranlara aşırı bă̆ımlı hale gelmiş, fizyolojik adaptasyonun bozulduğu hastalarda semptomların gerilemesine yardımcı olabilir.

Anahtar Kelimeler: Vertigo, migren, vestibüler, sersemlik, baş ağrısı

\section{Introduction and History}

The relationship between migraine and vertigo has been known for many years. This issue was first pointed out by the English physician Edward Living in 1873 (1). The term vestibular migraine (VM) was used by Boenheim (2) in 1917. The first case series of 90 patients with episodic vertigo and migraine was published by Dieterich and Brandt in (3) 1999, and VM was suggested as the term to be chosen to describe this clinical presentation. Neurotologic findings in patients with migraine were first published in 1984 by Dr. Altan Kayan who founded

Address for Correspondence/Yazışma Adresi: Pınar Yalınay Dikmen MD, Acibadem Mehmet Ali Aydinlar University School of Medicine, Department of Neurology, Istanbul, Turkey

Phone: +90 2123044444 E-posta: pinar.yalinay@acibadem.edu.tr ORCID: orcid.org/0000-0001-7112-2142

Received/Geliş Tarihi: 24.03.2020 Accepted/Kabul Tarihi: 27.08.2020

${ }^{\circ}$ Copyright 2020 by Turkish Neurological Society

Turkish Journal of Neurology published by Galenos Publishing House. 
the neurotology laboratory in Ege University Faculty of Medicine, and his colleague Dr. Hood (4). The diagnostic criteria for VM were proposed by Neuhauser et al. (5) in 2001. According to these criteria, patients with headache and vertigo are diagnosed as having "definite migrainous vertigo", and in patients in whom vertigo behaves like migraine, is associated with environmental, physiologic causes or triggers such as food and responds to migraine prophylaxis medications, a diagnosis of "possible migrainous vertigo" is recommended. There is no consensus on the terminology of VM in publications over the years, and the terms migrainous vertigo, migraine-related vertigo, migrainerelated dizziness, migraine-related vestibulopathy, and benign recurrent vertigo have been used as equivalents. Although VM did not find a place in the previous two classifications, it was included in the beta version of the International Classification of Headache Diseases (ICHD) in 2013 for the first time with the contributions of the Bárány Society and entered the third classification published in 2018 (Table 1) (6,7). The consensus on diagnostic criteria and terminology is considered a positive development in terms of standardization of selected patients in scientific studies and evaluation of the effectiveness of drug treatments.

\section{Epidemiology and Demography}

Two methods were used in studies on VM before the publication of the diagnostic criteria in 2013. The first was to investigate the frequency of vertigo in patients with migraine, and the second was to investigate the frequency of migraine in patients with peripheral vertigo. The frequency of vertigo in patients with migraine is higher than in the normal population. The prevalence of migraine in the community is $16 \%$, and the prevalence of vertigo is $7 \%$; the risk of coincidental coexistence of these two diseases is $1 \%$, but studies show that the comorbidity of migraine and vertigo is $3 \%$ (8). Symptoms of vertigo and dizziness are reported in $30-50 \%$ of patients with migraine $(9,10)$. In a study conducted in our country, the rate of vertigo in patients with migraine was found to be higher than in healthy controls and patients with tension headache (11). In patients with

Table 1. Third International Classification of Headache Diseases (7)

A- At least five episodes fullfiling criteria C and D

B- A current or past history of migraine without aura or migraine with aura

C- Vestibular symptoms of moderate or severe intensity, lasting between 5 minutes and 72 hours

D- At least half of episodes are associated with at least one of the following three migrainous features

1- Headache with at least two of the following four characteristics:

a- Unilateral location

b- Pulsating quality

c- Moderate or severe intensity

d- Aggravation by routine physical activity

2- Photonophobia and photophobia

3- Visual aura

E- Not better accounted for by another ICHD-3 diagnosis or by another vestibular disorder peripheral vertigo, the frequency of migraine is reported to be three times higher $(9,12)$. In a study in which patients who were consecutively admitted to an outpatient clinic were evaluated, it was reported that the prevalence of migraine increased 1.6 times in patients who were admitted to the dizziness outpatient clinic compared with the orthopedic outpatient clinic $(5,13)$. In addition, dizziness is reported more frequently in patients with migraine than in patients with tension headache, suggesting that there may be a pathologic relationship between migraine and dizziness $(4,14,15)$.

$\mathrm{VM}$ is the most common cause of recurrent spontaneous vertigo and is the most common vestibular disease after benign paroxysmal vertigo (BPPV). Its prevalence has been reported between 4.3$29.3 \%$ (16). The fact that the prevalence was so variable was thought to be due to the inclusion of patients with both definite and probable VM diagnoses in studies until the diagnostic criteria were published in the ICHD-beta (2013) (6). In a study conducted with new diagnostic criteria in the United States of America, the prevalence of VM was found as $2.7 \%$ (17). Despite the prevalence of VM and the frequent use of health-care by these patients, it is still an under-diagnosed disease. In a study, the number of patients who were sent to a tertiary dizziness center with a pre-diagnosis of VM was $1.8 \%$, whereas it was observed that $20 \%$ of the patients received this diagnosis (18).

The disease mainly affects the female sex; the frequency of the disease in women is $1.5-5$ times higher $(3,8,12,19,20)$. VM can be seen at any age, but it often emerges between the second and fifth decades (ages 4-74 years) (21). In some patients, vestibular symptoms become prominent during menopause (22). In a singlecenter clinical study, it was reported that VM frequently affected female patients in their 40s who had a history of migraine in themselves or their family (19). Epidemiologic studies show that migraine-related syndromes are the most common cause of vertigo and dizziness in children (23). BPPV affects $3 \%$ of children aged 6-12 years, and childhood BPPV and cyclic vomiting and paroxysmal torticollis are thought to be migraine precursor syndromes $(24,25,26)$.

Family history is important for both migraine and VM. In a study by Teggi et al. (25), it was observed that $70.2 \%$ of 252 patients with definite VM had a positive family history of migraine and $66.3 \%$ had vertigo (25). In that study, $69 \%$ of patients had at least one migraine precursor symptom (BBPV, cyclic vomiting, benign paroxysmal torticollis, abdominal pain) in childhood, and $42.8 \%$ had motion sickness. Although it is thought that genetics play a role in the pathogenesis due to this familial burden, mutations (CACNA2A or ATP1A2) in familial migraine syndromes (hemiplegic migraine or episodic ataxia) could not be found in VM $(27,28)$. Although there is no monogenic transition, polygenic inheritance may play a role in VM and it is recommended to research this subject $(26,29,30,31,32)$. Autosomal dominant inheritance was reported in some patients with migraine with decreased penetrance in men (26).

\section{Clinical Presentation}

\section{Relationship Between Headache and Vertigo}

The current criteria for VM require migraine headache or photophobia-phonophobia or visual aura accompanying at least half of the moderate or severe vestibular symptoms for diagnosis. 
In a patient with a suspected VM diagnosis, not having headache and vertigo at the same time can be a challenge for the physician. In patients with VM, headache usually begins before vertigo, headache may improve or continue, and vertigo may develop after years. In a study, it was reported that the time between the appearance of headache and vertigo was 8 years (33). The nature and duration of patients' migraine symptoms and their relationship with vestibular symptoms are frequently variable $(5,34)$. In the study by Teggi et al. (25) including patients with definite VM, it was reported that the mean age of headache was 23 (range, 11-40) years, and vestibular symptoms appeared at the age of 38 (rage, 16-60) years (24). In this study, the mean duration of vestibular symptoms was 52.8 (range, 2-360) months.

Some patients with VM do not meet the diagnostic criteria for migraine, and the headache described by the patients associated with vestibular symptoms is a feeling of pressure in the whole head, ear, sinuses or neck region (35). In some patients whose headache is compatible with the diagnostic criteria for migraine, the onset of vestibular symptoms and headache may not be simultaneous. Patients with migraine have lifelong characteristics of "hypersensitive brain" and may present with many different symptoms instead of headache (e.g. photophobia, phonophobia, motion sickness) (36). Triggers of migraine headache also often cause vestibular symptoms in patients. In a typical anamnesis, a patient with a past migraine headache identifies vestibular symptoms manifested by stress, air changes or food years later. Headache may or may not accompany or it may be in the form of a slight pressure sensation.

\section{Characteristics and Duration of Vertigo}

According to the Vestibular Symptoms Classification of the Bárány Society, vertigo or dizziness may occur in different ways in VM (37):

1- Spontaneous vertigo: The feeling of spinning internally or externally

2- Vertigo triggered by visual stimuli

3- Positional vertigo (occurring after head position change)

4- Vertigo triggered by head movement (occurring during head position change)

5- Dizziness and nausea triggered by head movement

Table 2. Vertigo can be defined in different ways by patients with vestibular migraine

- Feeling of internal rotation

- Feeling of swinging back and forth

- The sensation of the trunk bending sideways

- Swinging feeling to both sides

- Imbalance

- Feeling of emptiness in the head

- Blur in the head

- Disorder of feeling of place and time

- Being like drunk

- As a motion sickness or seasick

- As if swimming in water

- As if walking in the air

- As if coming down from a Ferris wheel

- As if an earthquake has occurred

- As if the earth is sliding under the feet
Forms of dizziness are currently not included in the diagnostic criteria of VM, but vertigo and dizziness can be expressed in many different ways by patients (Table 2) (38). An important clinical finding is that patients with VM often complain of pronounced motion sickness, especially on bad roads, stairs or elevators in which visuospacial orientation becomes difficult. Intolerance to head movement is the most frequently reported symptom in patients with VM $(31-77 \%)(39,40)$. Symptoms worsen with head movement and this often suggests BPPV, but BPPV cannot be demonstrated with the Dix-Hallpike test. In a study by Teggi et al. (25) in 2017, it was shown that $73 \%$ of patients defined internal vertigo, $47.2 \%$ pontaneous dizziness, $25 \%$ external vertigo, and $61.5 \%$ postural symptoms. Neuhauser et al. (41) reported that $67 \%$ of patients had spontaneous rotational vertigo and $24 \%$ had positional vertigo. In this study, concurrent vertigo headache was reported in only $24 \%$ of patients. In other studies, spontaneous vertigo was reported as $20-85 \%$, positional vertigo as $18-60 \%$, and intolerance to head movements as 30 $80 \%(3,4,19,25,39,40,42,43,44)$. These symptoms vary between individuals, the most frequently reported vestibular symptom is spontaneous vertigo, followed by positional vertigo $(5,45)$.

The duration of vestibular symptoms is highly variable $(3,4,5,42)$. Symptoms last for minutes in $30 \%$ of patients, hours in $30 \%$, days in $30 \%$, and seconds in $10 \%$ (37). In a small number of patients, vestibular symptoms appear as an aura for 5-60 minutes before the headache. In the study of Teggi et al. (25), the duration of vertigo attacks was less than 5 minutes in $28 \%$ of patients, $6-60$ minutes in $21.8 \%, 1-4$ hours in $11.5 \%, 5-24$ hours in $17.5 \%$, and up to 3 days in $5.5 \%$. It was reported to be longer than 3 days in $2.8 \%$ of patients and $3-7$ days in $2.8 \%$ of patients. These findings highlight the importance of the anamnesis and illustrate that a uniform conclusion cannot be drawn from the clinical findings of VM.

\section{Other Symptoms in Vestibular Migraine}

Nausea, vomiting, and motion sickness are common in patients with VM, but these symptoms can also be seen in other peripheral vestibulopathies; they are not specific for VM. Vestibular symptoms are considered to be of moderate severity when they affect daily living activities.

In one series, $70 \%$ of patients with VM reported photophobia, $60 \%$ phonophobia, and $36 \%$ migraine aura (5). In another study, $87 \%$ of patients had photophobia, $86 \%$ phonophobia, $64 \%$ headache, and $13 \%$ migraine aura (43). Temporary auditory symptoms such as pressure sensation in the ear and tinnitus have been defined by $40 \%$ of patients with VM $(4,39,43,45,46,47,48)$.

\section{Diseases Coexisting with Vestibular Migraine}

Studies have shown that BPPV is more common in patients with migraine than in healthy controls $(5,49,50)$ and that having migraine increases the risk of BPPV (51). It has been reported that the prevalence of Ménière's disease (MD) is also increased in patients with migraine compared with healthy individuals $(48,52,53,54)$. In a study, it was shown that $13 \%$ of the patients met both VM and MD diagnostic criteria (55).

Nine hundred eleven patients in the MD database in Finland were screened to investigate the relationship between MD and VM (56). Of the patients, $78.7 \%$ were female, their average age was 60.2 years, and their average duration of illness was 12.6 years. Of 
the patients, $20.9 \%$ had migraine and $42.9 \%$ had headache. The results of the study showed that patients with MD classified as VM had more severe symptoms, lower quality of life, higher anxiety, more neurologic symptoms, and greater difficulty in adapting to life events than patients without migraine. VM and MD cannot be reliably differentiated by advanced statistical analysis based on symptoms. In that study, it was stated that both headache and migraine were frequently seen together in $\mathrm{MD}$ and migraine increased the severity of MD. The authors, who thought that VM and MD shared similar pathophysiologic mechanisms, suggested that there should be a subcategory of "MD coexisting with migraine" in future MD classifications. In the study conducted by Neff et al. (48), it was concluded that the findings, symptoms or examinations used to differentiate patients with VM and MD from each other did not work in the differential diagnosis.

In another study, symptoms seen in patients with MD and probable and definite VM were compared (54). Auditory symptoms (tinnitus, fullness in the ears, hearing loss) were reported more frequently in $\mathrm{MD}$, and migraine symptoms (headache, photophobia/phonophobia, visual aura), anxiety and palpitations were observed to be predominant in VM. While VM is more common in women and at an early age, it has been reported that there is no specific symptom to distinguish the two diseases.

The prevalence of comorbid psychiatric diseases, especially depression and anxiety disorders, is high in patients with VM, as in patients with migraine (57). In a study conducted in our country, it was shown that patients with VM had more anxiety symptoms, agoraphobia, and separation anxiety compared with patients with migraine without vestibular findings and healthy controls and that they also needed more medical reassurance compared to other two groups (58).

The impairment of spatial orientation perception described by patients with VM is also seen in patients with persistent postural perceptual dizziness (PPPD), and psychiatric comorbidity is high in both diseases. In addition, the prevalence of migraine has increased with chronic visuospacial symptoms in PPPD (15$20 \%$ ); both diseases are diagnosed clinically and the pathogenesis is not fully known. It is thought that there may be a pathologic relationship between these two conditions due to their intertwined clinical features $(57,59)$.

\section{Clinical Findings and Laboratory Examinations}

In the literature, findings regarding central vestibulo-ocular anomalies, peripheral vestibular dysfunction, and vestibular evoked myogenic potentials (VEMP) in VM are inconsistent (60). In some studies, central vestibular dysfunction was found in patients with VM, whereas in other studies there were findings to support this, and some studies reported peripheral vestibular dysfunction $(3,40,61,62,63,64,65,66,67,68,69,70)$.

In patients with VM, neurotologic findings are often normal in the interictal period. However, some nonspecific mild vestibuloocular anomalies have been reported in association with VM such as tracking abnormalities (48\%), spontaneous nystagmus (10\%), and gaze-evoked nystagmus $(28 \%)(3,20,39,61,62,63)$. It has also been reported that these non-specific oculomotor abnormalities increase during follow-up (61). These findings are seen in young people whose central vestibular system is not expected to be affected, most patients cannot tolerate optokinetic stimulation or even head shaking, even on days when they state that they have no symptoms. The most common finding in electronystagmography is nausea triggered by optokinetic nystagmus and the patient's inability to complete four caloric irrigations due to excessive nausea.

During acute VM attacks, spontaneous nystagmus, positional nystagmus or their combinations can be seen (64). In the study of Beh et al. (19), the rate of positional vertigo during VM attacks was $25.2 \%$ and $13 \%$ outside of attacks. In studies, interictal positional nystagmus is present between $0 \%$ and $28 \%$ in patients with VM $(3,4,39,40,61)$. When evaluating positional vertigo, BPPV and VM may be confused, and detailed anamnesis and examination can help distinguish these two conditions. In a study, a unilateral decrease in peripheral vestibular function was reported in $25 \%$ of patients and vestibulo-ocular abnormality in 50\% (64).

In static posturography, increased oscillation $(39,62)$ and abnormality in ocular VEMP potentials were reported in patients with VM compared with healthy controls $(71,72,73,74)$. Hearing loss was found in approximately $8 \%$ of patients with VM. However, this loss was been reported as a mild, non-progressive hearing loss, unlike the progressive low-frequency hearing loss seen in $\operatorname{MD}(8,61,75)$.

\section{Pathophysiology}

The pathophysiology of VM has not been fully elucidated because the diagnosis is clinical and there is no reliable consistency in laboratory examinations in studies. In the pathophysiology of migraine, it is thought that individuals with migraine have "hypersensitive brain" as a result of genetic and environmental conditions, and the altered neural activity of the trigeminovascular system triggers headache and accompanying symptoms (Figure 1). When migraine attack begins as a result of intrinsic and extrinsic triggers, neuropeptides [substantially p, calcitonin gene-related peptide (CGRP)] released as a result of trigeminovascular system activation cause vasodilation and neurogenic inflammation. Then clinical headache occurs and central sensitization may cause allodynia. Some neurotransmitters in the central nervous system (serotonin, CGRP) are also found in the vestibular system and are thought to play a role in the pathophysiology of $\mathrm{VM}(76,77,78)$. The trigeminal nucleus is connected to the bilateral thalami, and the thalamus projects its signals to the temporal, parietal, insular, and cingulate cortical regions. In addition, nociceptive brainstem centers such as nucleus raphe magnus, periaquaductal gray matter, and hypothalamic areas are connected to the trigeminovascular system and vestibular nuclei $(79,80)$. These reciprocal relationships modulate both the trigeminovascular system and the vestibular nuclei. Trigeminal stimulation causes nystagmus to occur in people with migraine, which suggests that the excitability threshold in the vestibular nuclei is lower in migraineurs compared with healthy controls $(81,82)$. Spontaneous nystagmus or prolonged vestibular responses (such as long time constant in vestibular nystagmus) in patients with $\mathrm{VM}$ are evaluated in relation to vestibular hyperexcitability (83). However, it is not known whether this hyperexcitability originates from the peripheral vestibular system, the brainstem, or from the cerebellum or vestibular cortical centers that modulate them at higher levels.

Hypersensitivity to head movements and increased postural shaking observed in patients with VM suggest that there may be problems in visuospatial orientation or the processing and perception stages of sensory inputs and that this sensory pattern 
disinformation may play a role in the pathophysiology of VM. Imaging studies also support that there are functional changes in the temporoparietal regions in patients with VM and that the cortical regions in which sensory integration related to visuospatial perception are processed are also involved in the pathophysiology (84).

\section{Differential Diagnosis}

Table 3 summarizes the diseases that can be confused with VM (85). The differential diagnosis of VM should be made primarily with possible peripheral vestibular diseases. On the other hand, it should be kept in mind that migraine and peripheral vestibular diseases can frequently coexist. Early MD is the first to be excluded in the differential diagnosis. The most important feature that distinguishes VM from MD is hearing loss at low frequencies in MD. Patients with VM may also describe a feeling of pressure in the ear, tinnitus or even hearing loss, but hearing loss in VM is not progressive.

\section{Treatment}

Figure 2 shows the treatment steps in VM. The most important starting point in the treatment is to reveal the triggers that cause headache and vertigo and to arrange the person's lifestyle and diet accordingly. Triggers that cause migraine headache often cause vertigo attacks. These can be listed as skipping meals (prolonged hunger), sleep patterns changes, menstruation, air pressure changes, alcohol (especially red wine), sweeteners, processed meats, aged cheeses, excess caffeine consumption, monosodium glutamate, and chocolate. Not all triggers may initiate headaches and vertigo in every patient with migraine, so it is recommended that patients recognize the triggers that initiate or facilitate the emergence of their attacks and control them by keeping a headache and vertigo diary. In a study, it was reported that only caffeine discontinuation was effective in the treatment in $14 \%$ of patients with VM (86).
Acute treatment in headache and vertigo is performed to control the symptoms, and prophylactic treatment is performed to reduce the frequency of attacks and increase the quality of life. VM treatment is tailored to the individual. The most disturbing symptom or symptoms for the patient should be determined and a treatment plan should be made considering the patient's age, comorbid conditions, and adverse effects of the drugs.

\section{Drugs Used for Acute Attack Treatment}

The duration of vertigo attacks in VM is quite variable, ranging from seconds to days. Duration varies between patients as well as between individual episodes in the same patient. Acute treatment is required for prolonged and frequent vertigo attacks. During vertigo attacks, $20 \%$ of patients benefit from drugs that suppress the vestibular system (35). Drugs and antiemetics used in the treatment of acute vertigo may be useful in suppressing vestibular symptoms (87). In patients with VM, centrally acting promethazine $(15 \mathrm{mg}$ or $50 \mathrm{mg}$ ) increases the absorption of orally administered drugs by controlling nausea and vomiting with its antivertiginous, antiemetic, and sedative effects. Metoclopramide or domperidone increases the absorption of orally administered drugs by controlling nausea and vomiting with its antiemetic effect and improving gastrointestinal motility. These drugs can be used in the treatment of headache and vertigo attacks. The antihistaminic dimenhydrinate and meclizine may also be useful in controlling vertigo and motion sickness.

Studies have been conducted with triptans in the acute treatment of VM $(88,89,90)$. Almotriptan $(\mathrm{n}=12)$ and sumatriptan $(\mathrm{n}=53)$ were tested in two retrospectively designed studies. It was reported that sumatriptan was effective in the treatment of migraine-related dizziness and vertigo attacks, and decreasing both headache and vertigo. Other drugs such as ergot derivatives, non-steroidal antiinflammatory drugs and opioids used in the treatment of acute migraine attacks also had partial efficacy for headache and dizziness (91).

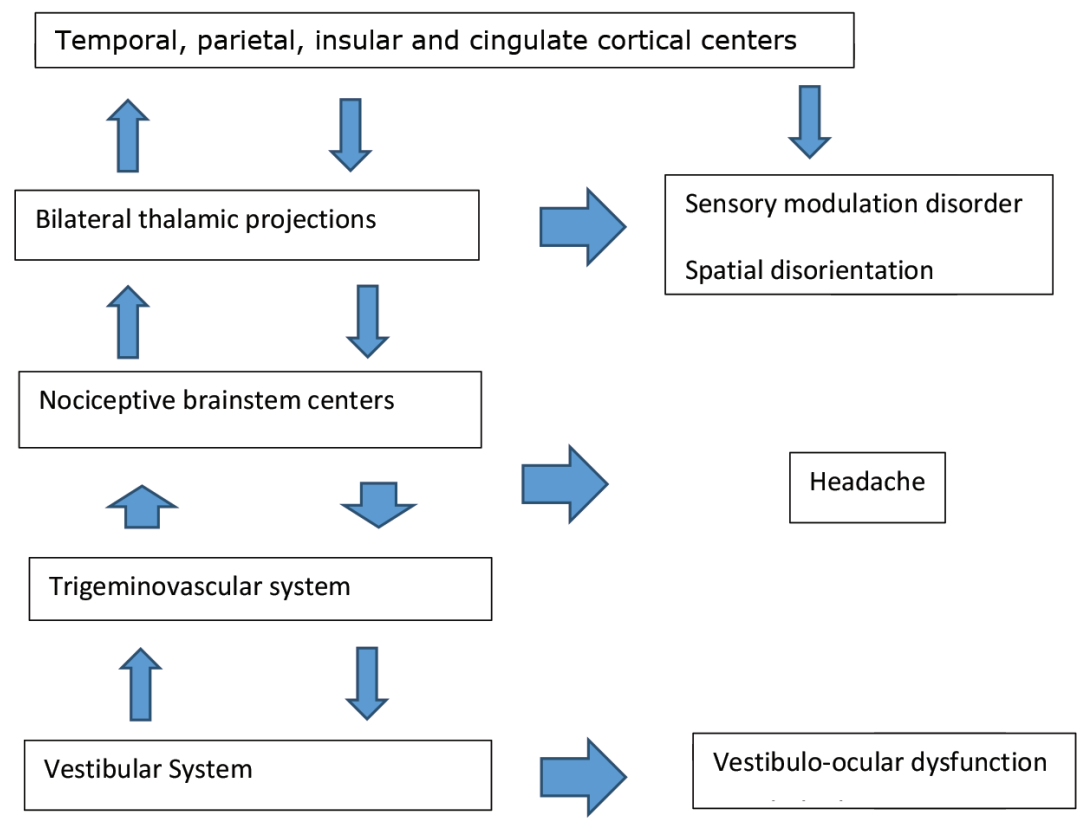

Figure 1. Pathophysiology of vestibular migraine 
In a randomized, double-blind placebo-controlled study using zolmitriptan $(\mathrm{n}=10)$, it was reported that in patients given a dose of $2.5 \mathrm{mg}$ during VM attacks, zolmitriptan (38\%) provided a more significant improvement in vertigo recovery compared with placebo $(22 \%)$ after 2 hours (90). However, due to the limited power of that study, the results did not reach statistical significance.

It was reported that in patients with migraine with vestibular motion sickness, rizatriptan showed efficacy on serotonergic vestibulo-autonomic pathways when compared with placebo (92). It was reported that steroid injections were also effective in four patients with VM with prolonged or frequent vertigo attacks (93).

\section{Drugs Used for Preventive Treatment}

If VM attacks are frequent and impair quality of life by affecting daily life activities, it is recommended to initiate preventive treatment for the inhibition of cortical hypersensitivity and restructuring of nociceptive dysmodulation. Drugs used in the treatment of migraine have also been tried for VM, but there is confusion in the interpretation of the results. Some studies on this subject were conducted before the diagnostic criteria for VM were published in 2013 and it was not known to what extent the included patients met the present VM criteria $(94,95)$. In addition, because most of these studies involved small numbers of subjects and that the information from randomized controlled studies was lacking, there is a need for prospective, randomized, and controlled studies in this field (85).

Although beta-adrenergic blockers, calcium channel blockers, and antiepileptic drugs are effective in the treatment of migraine, their role in VM treatment is not fully clear. In a prospective, randomized, non-placebo-controlled study, flunarizine was shown to reduce the frequency and severity of vertigo attacks in patients with VM (93). In another study with a retpospective design, cinnarizine $75 \mathrm{mg}$ also reduced the frequency of vertigo attacks in patients with VM (96). Selective serotonin reuptake inhibitors (SSRI) and serotonin-noradrenaline reuptake inhibitors have also been studied in VM; these drugs may be particularly useful in patients with psychiatric comorbidities $(97,98)$. Liu et al. (99) compared venflaxine $(37.5 \mathrm{mg})$, flunarizine $(10 \mathrm{mg})$, and valproic acid $(1000 \mathrm{mg}$ ) in 25 patients with VM and followed up these patients for 3 months. All three drugs showed efficacy in patients with VM. In a prospective, randomized-controlled study $(n=33)$ in which Salviz et al. (100) used propronolol in a dose range of 40-160 mg, and the Dizziness Disability Questionnaire score and

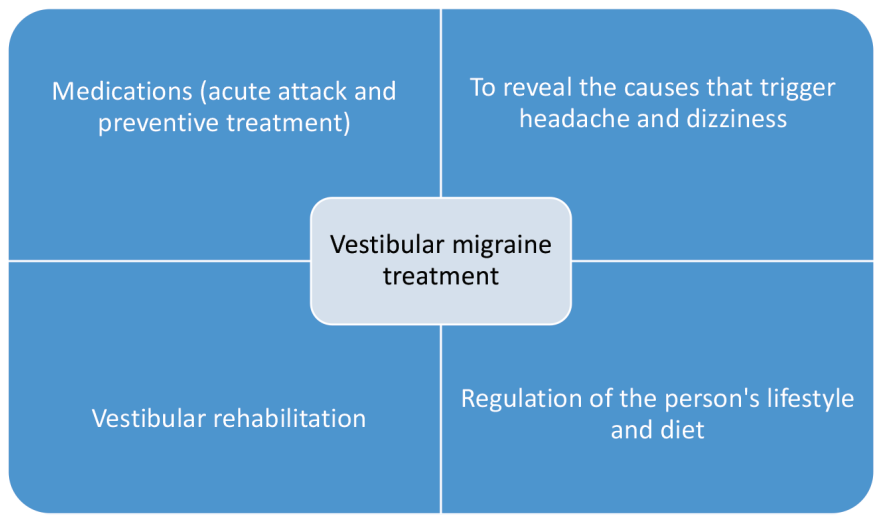

Figure 2. Vestibular migraine treatment
Table 3. The diseases that should be kept in mind in the differential diagnosis of vestibular migraine are listed below

\section{1- Meniérè's disease}

Clinical presentation: Unilateral tinnitus, hearing loss and fullness in the ear

Diagnostic tests: Audiometry is useful for demonstrating hearing loss. The use of ENG/VNG is limited. The caloric test can show vestibular dysfunction in the ear with hearing loss

2- Vestibular neuronitis or labyrinth

Clinical presentation: Acute onset peripheral vestibular involvement

Diagnostic tests: In clinical examination, HINTS (head impulse, nystagmus, test of skew) can help distinguish peripheral and central vertigo. Imaging studies are usually normal and may not be necessary if the history and examination are compatible with peripheral vestibulopathy

\section{3- Semicircular canal separation syndrome}

Clinical presentation: Pressure, loud noise and cough can provoke symptoms.

Diagnostic tests: Although the diagnostic criteria are not clear, temporal computed tomography (CT) may be useful

\section{4- Benign paroxysmal positional vertigo}

Clinical presentation: Attacks of vertigo lasting less than 1 minute without hearing loss or tinnitus

Diagnostic tests: Dix-Hallpike maneuver for posterior BPPV or supine roll test for horizontal BPPV can be performed at the bedside with an examination

\section{5- Herpes zoster oticus (Ramsay Hunt)}

Clinical presentation: Rapid onset ear pain, acute vertigo, hearing loss

Diagnostic tests: Detecting ipsilateral facial paralysis and vesicles in the ear by examination

\section{6- Stroke (ischemic or hemorrhagic) and vertebrobasilar} insufficiency

Clinical presentation: Sudden onset of cerebellar and brainstem findings

Diagnostic tests: Neurological examination and HINTS are important in separating the causes of central and peripheral vertigo. Although diffusion magnetic resonance imaging (MRI) is $20 \%$ false negative in the first 24 hours in brainstem strokes, it should be planned first. If hemorrhage is suspected, brain CT should be performed as the first option

\section{7- Migraine with brain stem aura}

Clinical presentation: Transient brainstem symptoms in a young patient without motor findings, followed by headache compatible with migraine diagnosis criteria.

Diagnostic tests: Absence of diffusion MRI findings consistent with acute stroke on radiological examination

8- Persistent postural perceptual dizziness (postural phobic vertigo, chronic subjective dizziness)

Clinical presentation: Non-rotational dizziness or vertigo is present. The patient has difficulty performing visual tasks, and there is an increased sensitivity to moving stimuli. According to the diagnostic criteria, the patient's complaints should continue for at least 3 months.

Diagnostic tests: There is no diagnostic test, but there may be a decrease in habituation of the nociceptive blink reflex 
Vertigo Severity score and the number of attacks per month were statistically decreased.

In a retrospective review, 79 patients with migraine-related dizziness and vertigo were evaluated (46). Benzodiazepines (often clonazepam), tricyclic antidepressants (amitriptyline or nortriptyline), beta-blockers (propranolol), SSRI drugs (fluoxetine, sertraline, paroxetine), and calcium channel blockers (verapamil or diltiazem) were used. Of the patients, $92 \%$ with episodic vertigo, $89 \%$ with positional vertigo, and $86 \%$ with non-vertiginous dizziness reported improvement in their symptoms. Of the patients, $44 \%$ used one, $33 \%$ double, and the rest 3-6 drugs.

Acetazolamide $(500 \mathrm{mg} / \mathrm{g}$, in divided doses) was studied in 50 patients with VM in a retrospective single-center study (101). The average frequency of vertigo attacks decreased from 3.9 to 1.4 and the frequency of headache attacks decreased from 4.31 to 2.85 in three months. Six patients were excluded due to adverse effects. The visual analog scale score of patients with VM decreased from 5.6 to 2.3 .

In a retrospective, observational study in which 19 patients with VM treated using lamotrigine $100 \mathrm{mg}$ /day for 3-4 months were evaluated retrospectively, the frequency of vertigo attacks per month decreased from 18.1 to 5.4 , but there was no statistically significant change in the average headache frequency (98).

In a recent study by Celik et al. (102), propranolol was used in 38 patients with a diagnosis of definite VM. It was reported that this treatment reduced the severity, frequency and number of attacks, and disability scores, and also increased the quality of life of patients.

\section{Vestibular Rehabilitation}

Although many studies report that vestibular rehabilitation is beneficial in VM, there is no randomized controlled study showing that vestibular physical therapy is effective (103). Vestibular rehabilitation is especially recommended for patients who become overly dependent on environmental and visual stimuli and whose physiologic adaptation is impaired. Activities that increase visual and spatial orientation and body coordination, such as dance, pingpong, and disciplines such as yoga, Tai-Chi and ballet may help reduce the symptoms of patients.

Adaptation exercises, which are used as the first choice in vestibular rehabilitation, aim at the adaptation of the vestibulo-ocular reflex through head and eye movements $(104,105)$. Habituation exercises aim to control symptoms by constantly repeating the trigger movements that cause the symptoms. Horizontal head movements, circling using a ball, head-turning movements and head-turning exercises while walking can be performed. Substitution exercises include static and dynamic exercises to help patients improve the use of proprioceptive afferents.

\section{Conclusion}

$\mathrm{VM}$ is a clinical diagnosis made in patients with recurrent vestibular symptoms, when a relationship is established between migraine history and vestibular symptoms, and when other possible etiologic causes are excluded. Although awareness of VM has increased in recent years, it is still an under-diagnosed disease. Variations in clinical findings can make the diagnosis of VM difficult. In patients with VM, symptoms worsen with a change of position and movement of the person or environment.
In the differential diagnosis, the first thing to consider is MD and approximately $50 \%$ of these patients experience at least one migraine symptom in their attacks. In this context, VM must be considered in a differential diagnosis before a destructive treatment is initiated in MD. Drugs used in migraine treatment can be tried for acute and prophylactic treatment, but prospective, randomized and controlled studies are needed to establish evidence-based treatment in VM.

\section{Ethics}

Peer-review: Externally and internally peer-reviewed.

Financial Disclosure: The author declared that this study received no financial support.

\section{References}

1. Liveing E. On megrim, sick headache and some allied health disorders: a contribution to the pathology of nerve storms. London: Churchill, 2010:129-148.

2. Boenheim F. Über familiäre Hamicrania vestibularis. Neurol Centralbl 1917;36:226-229.

3. Dieterich M, Brandt T. Episodic vertigo related to migraine (90 cases): vestibular migraine? J Neurol 1999;246:883-892.

4. Kayan A, Hood JD. Neuro-otological manifestations of migraine. Brain 1984;107;1123-1142.

5. Neuhauser H, Leopold M, von Brevern M, Arnold G, Lempert T. The interrelations of migraine, vertigo and migrainous vertigo. Neurology 2001;56:436-441.

6. Headache Classification Committee of the International Headache Society (IHS). The international classification of headache disorders, 3rd edition (beta version). Cephalalgia 2013;33:629-808.

7. Headache Classification Committee of the International Headache Society (IHS). The international classification of headache disorders, 3rd edition. Cephalalgia 2018;38:1-211.

8. Lempert T, Neuhauser H. Epidemiology of vertigo, migraine and vestibular migraine. J Neurol 2009;256:333-338.

9. Vukovic V, Plavec D, Galinovic I, et al. Prevalence of vertigo, dizziness, and migrainous vertigo in patients with migraine. Headache 2007;47;14271435

10. Cha YH, Lee H, Santell LS, Baloh RW. Association of benign recurrent vertigo and migraine in 208 patients. Cephalalgia 2009;29:550-555.

11. Akdal G, Baykan B, Ertas M, et al. Population-based study of vestibular symptoms in migraineurs. Acta Otolaryngol 2015;135:435-439.

12. Kuritzky A, Ziegler DK, Hassanein R. Vertigo, motion sickness and migraine. Headache 1981;21:227-231.

13. Lee H, Sohn SI, Jung DK, et al. Migraine and isolated recurrent vertigo of unknown cause. Neurol Res 2002;24:663-665.

14. Akdal G, Özge A, Ergör G. The prevalence of vestibular symptoms in migraine and tension-type headache. J Vestib Res 2013;23:101-106.

15. Eggers SDZ, Staab JP, Neff BA, et al. Investigation of the coherence of definite and probable vestibular migraine as distinct clinical entities. Otol Neurotol 2011;32:1144-1151.

16. Sohn JH. Recent advances in the understanding of vestibular migraine. Behav Neurol 2016;2016:1801845.

17. Formeister EJ, Rizk HG, Kohn MA, Sharon JD. The epidemiology of vestibular migraine: a population-based survey study. Otol Neurotol 2018;39:1037-1044.

18. Geser E, Straumann D. Referral and final diagnoses of patients assessed in an academic vertigo center. Front Neurol 2012;3:169.

19. Beh SC, Masrour S, Smith SV, Friedman DI. The spectrum of vestibular migraine: clinical features, triggers, and examination findings. Headache 2019;59:727-740.

20. Casani AP, Sellari-Franceschini S, Napolitano A, Muscatello L, Dallan I. Otoneurological dysfunctions in migraine patients with or without vertigo. Otol Neurotol 2009;30:961-967.

21. Hsu LC, Wang SJ, Fuh JL. Prevalence and impact of migrainous vertigo in mid-life women: a community-based study. Cephalalgia 2011;31:77-83. 
22. Park JH, Viirre E. Vestibular migraine may be an important cause of dizziness/ vertigo in perimenopausal period. Med Hypotheses 2010;75:409-414.

23. Jahn K, Langhagen T, Heinen F. Vertigo and dizziness in children. Curr Opin Neurol 2015;28:78-82.

24. Abu-Arafeh I, Russell G. Paroxysmal vertigo as a migraine equivalent in children: a population-based study. Cephalalgia 1995;15:22-25; discussion 4.

25. Teggi R, Colombo B, Albera R, et al. Clinical features, familial history, and migraine precursors in patients with definite vestibular migraine: the VMphenotypes projects. Headache 2018;58:534-544.

26. Lee H, Jen JC, Cha YH, Nelson SF, Baloh RW. Phenotypic and genetic analysis of a large family with migraine-associated vertigo. Headache 2008;48:1460-1467.

27. Kim JS, Yue Q, Jen JC, Nelson SF, Baloh RW. Familial migraine with vertigo: No mutation found in CACNA1A. Am J Med Genet 1998;79:148-151.

28. von Breven M, Ta N, Shankar A, et al. Migrainous vertigo: mutation analysis of the candidate genes CACNA1A, ATP1A2, and CACNB4. Headache 2006;46:1136-1141.

29. Bahmad F, DePalma SR, Merchant SN, et al. Locus for familial migrainous vertigo disease maps to chromosome 5q35. Ann Otol Rhinol Laryngol 2009;118:670-676.

30. Baloh RW. Migraine and vertigo: epidemiology, genetics, and mechanism(s). Headache Curr 2006;3:1-7.

31. Lee H, Jen JC, Wang $\mathrm{H}$, et al. A genome-wide linkage scan of familial benign recurrent vertigo: linkage to $22 \mathrm{q} 12$ with evidence of heterogeneity. Hum Mol Genet 2006;15:251-258.

32. Nyholt DR, Morley KI, Ferreira MAR, et al. Genome-wide significant linkage to migrainous headache on chromosome 5q21. Am J Hum Genet 2005;77:500-512.

33. Thakar A, Anjaneyulu C, Deka RC. Vertigo syndromes and mechanisms in migraine. J Laryngol Otol 2001;115:782-787.

34. Cha YH, Chi Y. Rocking dizziness and headache: a two-way street. Cephalalgia 2013;33:1160-1169.

35. Mehle ME. Sinus headache, migraine, and the otolaryngologist. Switzerland: Springer, 2017.

36. Colombo B, Teggi R. Vestibular migraine and related syndromes. Switzerland: Springer, 2014.

37. Bisdorffa A, von Brevern M, Lempert T, Newman-Toker DE. Classification of vestibular symptoms: towards an international classification of vestibular disorders. J Vestib Res 2009;19:1-13.

38. Furman JM, Balaban CD. Vestibular migraine. Ann N Y Acad Sci 2015;1343:90-96.

39. Cass SP, Furman JM, Ankerstjerne K, et al. Migraine-related vestibulopathy. Ann Otol Rhinol Laryngol 1997;106:182-189.

40. Cutrer FM, Baloh RW. Migraine-associated dizziness. Headache 1992;32:300-304.

41. Neuhauser HK, Radtke A, von Brevern M, et al. Migrainous vertigo: prevalence and impact on quality of life. Neurology 2006;67:1028-1033.

42. Zhang Y, Kong Q, Chen J, et al. International classification of headache disorders 3rd edition beta-based field testing of vestibular migraine in China: demographic, clinical characteristics, audiometric findings and diagnosis statues. Cephalalgia 2016;36:240-248.

43. Cohen JM, Bigal ME, Newman LC. Migraine and vestibular symptomsidentifying clinical features that predict "vestibular migraine". Headache 2011;51:1393-1397.

44. Dieterich M, Staab JP, Brandt T. Functional (psychogenic) dizziness. Handb Clin Neurol 2016;139:447-468.

45. Dietrich M, Obermann M, Celebisoy N. Vestibular migraine: the most frequent entity of episodic vertigo. J Neurol 2016;263:82-89.

46. Johnson GD. Medical management of migraine-related dizziness and vertigo. Laryngoscope 1998;108:1-28.

47. Kırkım G, Mutlu B, Olgun Y, et al. Comparison of audiological findings in patients with vestibular migraine and migraine. Turk Arch Otorhinolaryngol 2017;55:158-161.

48. Neff BA, Staab JP, Eggers SD, et al. Auditory and vestibular symptoms and chronic dizziness in patients with Meniere's disease with concomitant vestibular migraine. Otol Neurotol 2012;33:1235-1244.

49. Ishiyama A, Jacobson KM, Baloh RW. Migraine and benign positional vertigo. Ann J Otol Rhinol Laryngol 2000;109:377-380.
50. Lempert T, Leopold M, von Brevern M, Neuhauser H. Migraine and benign positional vertigo. Ann Otol Rhinol Laryngol 2000;109(12 Pt 1):1176.

51. Chu CH, Liu CJ, Lin LY, Chen TJ, Wang SJ. Migraine is associated with an increased risk for benign paroxysmal positional vertigo: A nationwide population-based study. J Headache Pain 2015;16:62.

52. Radtke A, Lempert T, Gresty MA, et al. Migraine and Meniere's disease: is there a link? Neurology 2002;59:1700-1704.

53. Ghavami Y, Mahboubi H, Yau AY, Maducdoc M, Djalilian HR. Migraine features in patients with Meniere's disease. Laryngoscope 2016;126:163168.

54. Lopez-Escamez JA, Dlugaiczyk J, Jacobs J, et al. Accompanying symptoms overlap during attacks in Meniere's disease and vestibular migraine. Front Neurol 2014;5:265.

55. Cha YH, Kane MJ and Baloh RW. Familial clustering of migraine, episodic vertigo, and Meniere's disease. Otol Neurot 2008;29:93-96.

56. Pyykö I, Manchaiah V, Farkkila M, Kentala E, Zou J. Association between Meniere's disease and vestibular migraine. Auris Nasus Larynx 2019;46:724733.

57. Beh SC, Masrour S, Smith SV, Friedman DI. The spectrum of vestibular migraine: clinical features, triggers, and examination findings. Headache 2019;59:727-740.

58. Kutay O, Akdal G, Keskinoglu P, Donmez Balc1 B, Alkın T. Vestibular migraine patients more anxious than migraine patients without vestibular symptoms. J Neurol 2017;264(Suppl 1):37-41.

59. Staab JP, Eckhardt-Henn A, Horii A, et al. Diagnostic criteria for persistent postural-perceptual dizziness (PPPD): consensus document of the committee for the classification of Vestibular Disorders of the Barany Society. J Vestib Res 2017;27:191-208.

60. Huang TC, Wang SJ, Kheradmand A. Vestibular migraine: an update on current understanding and future directions. Cephalalgia 2020;40:107-121.

61. Radtke A, von Brevern M, Neuhauser H, Hottenrott T, Lempert T. Vestibular migraine: long-term follow-up of clinical symptoms and vestibule-cochlear findings. Neurology 2012;79:1607-1614.

62. Celebisoy N, Gokcay F, Sirin H, Biçak N. Migrainous vertigo: clinical, oculographic and posturographic findings. Cephalalgia 2008;28:72-77.

63. Bolding MI, Ljostad U, Mygland A, Monstad P. Comparison of interictal vestibular function in vestibular migraine vs migraine without vertigo. Headache 2013;53:1123-1133.

64. von Brevern M, Zeise D, Neuhausser H, Clarke AH, Lempert T. Acute migrainous vertigo: clinical and oculographic findings. Brain 2005;128;365374.

65. Furman JM, Marcus DA. Migraine and motion sensitivity. Continuum. 2012;18:1102-1117.

66. von Brevern M. Acute migrainous vertigo: Clinical and oculographic findings. Brain 2004;128:365-374.

67. Furman JM, Sparto PJ, Soso M, Marcus D. Vestibular function in migrainerelated dizziness. A pilot study. J Vestib Res 2005;15:327-332.

68. Bir LS, Ardiç FN, Kara CO, et al. Migraine patients with or without vertigo: comparison of clinical and electronystagmographic findings. J Otolaryngol 2003;32:234-238.

69. Bath AP, Walsh RM, Ranalli P, et al. Experience from a multidisciplinary “dizzy" clinic. Am J Otol 2000;21:92-97.

70. Savundra P, Carroll J, Davies R, Luxon L. Migraine-associated vertigo. Cephalalgia 1997; 17:505-510.

71. Teggi R, Colombo B, Bernasconi L, et al. Migrainous vertigo: results of caloric testing and stabilometric findings. Headache 2009;49:435-444.

72. Boldingh MI, Ljostad U, Mygland A, Monstad P. Vestibular sensitivity in vestibular migraine: VEMPs and motion sickness susceptibility. Cephalalgia 2011;31:1211-1219.

73. Zaleski A, Bogle J, Starling A, et al. Vestibular evoked myogenic potentials in patients with vestibular migraine. Otol Neurotol 2015;36:295-302.

74. Makowiec KF, Piker EG, Jacobson GP, Ramadan NM, Roberts RA. Ocular and cervical vestibular evoked myogenic potentials in patients with vestibular migraine. Otol Neurotol 2018;39:e561-e567.

75. Battissa RA. Audiometric findings of patients with migraine-associated dizziness. Otol Neurotol 2004;25:987-992.

76. Durham PL. Calcitonin gene-related peptide (CGRP) and migraine. Headache 2006;46(Suppl 1):S3-S8. 
77. Ahn SK, Balaban CD. Distribution of 5-HT1B and 5-HT1D receptors in the inner ear. Brain Res 2010;1346:92-101.

78. Koo JW, Balaban CD. Serotonin-induced plasma extravasation in the murine inner ear: possible mechanism of migraine-associated inner ear dysfunction. Cephalalgia 2006;26:1310-1319.

79. Akerman S, Holland PR, Goadsby PJ. Diencephalic and brainstem mechanisms in migraine. Nat Rev Neurosci 2011;12:570-584.

80. Halberstadt AL, Balaban CD. Organisation of projections from the raphe nuclei to the vestibular nuclei in rats. Neuroscience 2003;120:573-594.

81. Marano E, Marcelli V, Di Stasio E, et al. Trigeminal stimulation elicits a peripheral vestibular imbalance in migraine patients. Headache 2005; $45: 325-331$.

82. Vass Z, Steyger PS, Hordickok AJ, et al. Capsaicin stimulation of the cochlea and electric stimulation of the trigeminal ganglion mediate vascular permeability in cochlear and vertebro-basilar arteries: a potential cause of inner ear dysfunction in headache. Neuroscience 2001;103:189-201.

83. King S, Wang J, Priesol AJ, Lewis RF. Central integration of canal and otolith signals is abnormal in vestibular migraine. Front Neurol 2014;5:233.

84. Obermann M, Wurthmann S, Steinberg BS, et al. Central vestibular system modulation in vestibular migraine. Cephalalgia 2014;34:1053-1061.

85. Lauritsen CG, Marmura MJ. Current treatment options: vestibular migraine. Curr Treat Options Neurol 2017;19:38.

86. Mikulec AA, Farji F, Kinsella LJ. Evaluation of the efficacy of caffeine cessation, nortriptyline, and topiramate therapy in vestibular migraine and complex dizziness of unknown etiology. Am J Otolaryngol 2012;33:121127.

87. Baloh RW. Neurotology of migraine. Headache 1997;37:615-621.

88. Cassano D, Pizza V, Busillo V. P074. Almotriptan in the acute treatment of vestibular migraine: a retrospective acute treatment of vestibular migraine: a retrospective study. J Headache Pain 2015;16(Suppl 1):A114.

89. Maione A. Migraine-related vertigo: diagnostic criteria and prophylactic treatment. Laryngoscope 2006;116:1782-1786.

90. Neuhausser H, Radtke A, von Brevern M, Lempert T. Zolmitriptan for treatment of migrainous vertigo: a pilot randomized placebo-controlled trial. Neurology 2003;60:882-883.

91. Bikhazi P, Jackson C, Ruckenstein MJ. Efficacy of antimigrainous therapy in the treatment of migraine-associated dizziness. Am J Otol 1997;18:350354.
92. Furman JM, Marcus DA, Balaban CD. Rizatriptan reduces vestibularinduced motion sickness in migraineurs. J Headache Pain 2011;12:81-88.

93. Prakash S, Shah ND. Migrainous vertigo responsive to intravenous methylprednisolone: case reports. Headache 2009;49:1235-1239.

94. Fernandez MM, Birdi JS, Irving GJ, et al. Pharmacological agents for prevention of vestibular migraine. Cochrane Database Syst Rev 2015;2015:CD010600.

95. Lepcha A, Amalanathan S, Augustine M, Tyagi AK, Balraj A. Flunarizine in the prophylaxis of migrainous vertigo: a randomized controlled trial. Eur Arch Otorhinolaryngol 2014;271:2931-2936.

96. Taghdiri F, Togha M, Razeghi Jahromi S, Rafeaian F. Cinnarizine for the prophylaxis of migraine associated vertigo: a retrospective study. Springerplus 2014;3:231

97. Jackson JL, Cogbill E, Santana-Davila R, et al. A comparative effectiveness meta-analysis of drugs for the prophylaxis of migraine headache. PLoS One 2015;10:e0130733.

98. Bisdorff AR. Treatment migraine related vertigo with lamotrigine an observational study. Bull Soc Sci Med Grand Duche Luxemb 2004:103-108.

99. Liu F, Ma T, Che X, Wang Q, Yu S. The efficacy of venlafaxine, flunarizine, and valproic asid in prophylaxis of vestibular migraine. Front Neurol 2017;8:524.

100. Salviz M, Yuce T, Acar H, Karatas A, Acikalin RM. Propranolol and venlafaxine for vestibular migraine prophylaxis: a randomized controlled trial. Laryngoscope 2016;126:169-174.

101. Celebisoy N, Gokcay F, Karahan C, et al. Acetazolamide in vestibular migraine prophylaxis: a retrospective study. Eur Arch Otorhinolaryngol 2016;273:2947-2951.

102. Celik O, Tanyeri Toker G, Eskiizmir G, İncesulu A, Sahin Süyür N. The Effectiveness of medical prophylactic treatment on vestibular migraine and its effect on the quality of life. J Int Adv Otol 2020;16:28-33.

103. Alghadir AH, Answer S. Effects of vestibular rehabilitation in the management of a vestibular migraine: a review. Front Neurol 2018;9:440.

104. Writer HS, Arora RD. Vestibular rehabilitation: an overview. Int J Otorhinolaryngol Clin 2012;4:54-69.

105. Boyer FC, Percebois-Macadre L, Regrain E, et al. Vestibular rehabilitation theraphy. Neurohysiol Clin 2008;38:479-487. 